\title{
Frame modal analysis for an electric three-wheel vehicle
}

\author{
Faizal Arifurrahman ${ }^{1,2, *}$, Indrawanto Indrawanto ${ }^{1,2}$, Bentang Arief Budiman ${ }^{1,2}$, Poetro Lebdo Sambegoro ${ }^{1,2}$, and Sigit Puji \\ Santosa ${ }^{1,2}$ \\ ${ }^{1}$ Faculty of Mechanical and Aerospace Engineering, Institut Teknologi Bandung, Jalan Ganesha 10 Bandung 40132, Indonesia \\ ${ }^{2}$ National Center for Sustainable Transportation Technology, Indonesia
}

\begin{abstract}
The alternative electric vehicle for delivery (E-Trike) is a developing three-wheel electric vehicle for goods delivery. Small size and its three-wheel mobility are required for flexible manoeuvrability on urban space due to traffic, parking and alley road. In this study, three different Alpha frames (Alpha-0, Alpha-1, and Alpha-2) of E-Trike vehicle are analysed using numerical simulation LS-DYNA. This study is conducted to obtain the modal response E-Trike vehicle. Eigenvalues of dynamics properties are investigated to avoid a resonance on excitation frequency. LS-DYNA implicit simulation used for simulating quadrangular shell element for the surface geometry of the frames. Boundary conditions are applied to the steering and suspension joints represent the real field. The result shows the amplitudes and the natural frequencies of Alpha frames. Bending mode and torsion mode can be determined. Based on the simulation, there is a pattern of vibration modes. Alpha-2 which is the latest version of three configurations has better response on vibration modes. There is about $3 \%$ reduction of vibration amplitude at Alpha- 2 than Alpha-0 and Alpha-1. Natural frequency response for each mode occurs at similar range. Furthermore, a shifted natural frequency of Alpha-2 combination mode occurs due to addition of the stretched frame.
\end{abstract}

\section{Introduction}

Three-wheel electric vehicle (E-Trike) for good delivery is developed to fulfil Indonesian goods delivery demand. The vehicle which implements extended-range electric vehicle technology is a part of vehicle collaboration project of NCSTT. A three-wheel driving system is applied considering delivery objective to carry the amount of goods with flexible movement on urban space. The project aims to improve urban transport in terms of green energy with minimal carbon emission. The complex urban condition with various requirements of this vehicle is recognised. As a consequence, vehicle design is required to be manoeuvrable enough and has good mobility.

Furthermore, to reduce structural weight and ensure the safety, E-Trike chassis has to be designed, optimised and validated carefully. Chassis structure requires comprehensive engineering analysis prior to be manufactured. Static and dynamic investigation has to be conducted to determine chassis strength rigidity. A dynamic requirement is a modal analysis which is investigating the natural frequency of structure and determining the vibration modes. By applying this investigation, the chassis structure could be re-designed and optimised depends on the analysis result. The concept of developing three-wheel vehicle is actually not new. CLEVER (Compact Low Emission Vehicle for Urban Transport) is a small, three-wheel vehicle that developed under funding of European Commission [1, 2]. Two-seater vehicle with natural gas engine power source has tilting mechanism. CLEVER is designed with special restraint system and very stiff frame structure.

A future vehicle has been studied in many works to determine the definition and aspect that should be desired in the next vehicle development. Suspension system to comfort the occupant as one aspect has been studied by $\mathrm{Cao}$ et al. and presented potential research topics associated with vehicle ride, handling, and stability of electric vehicle [3]. Jusuf et al. studied the safety aspect by experiment and numerically executed the thin walled crash box $[4,5]$.

The numerical study used to determine modal analysis for a mechanical dynamic system has been done in numerous previous works. Zolotarevicha et al. [6] conducted a numerical analysis of Runner of Francis Turbine. The result of numerical simulation has a good agreement with the numerical calculation of fundamental theory for turbine runner. Empirical equation compared by numerical study of the elastic rotor has been studied shows that similar natural frequency range [7]. Fluid study of natural frequencies was also investigated to find out the influence of the acoustic of a cylindrical fluid to identify the dynamic response of the disk-like structure. Zhu et al. [8] evaluated and improved the belt system after simulated the first design of belt system based on the modal analysis. Turcanu et al. [9] investigated the natural frequencies of ground movement system of a developed drone. The numerical study value showed higher than the experimental result. This is caused by finer mesh that is required. The result of this study also used for modification the next system by increasing the

\footnotetext{
* Corresponding author: faizal.arifurrahman@gmail.com
} 
natural frequency properties. Most of the previous works result is used for improving the further design. Design evaluation was conducted by the earlier design to determine the proper agreement between the carried loading and the structure configuration due to its dynamics properties and response.

It is necessary to determine the dynamical properties (e.g. natural frequencies, mode of shapes and damping factor) [10]. Variations of natural frequencies at the same mode caused by changes of multiple design variables. Natural frequency investigation is important in the design of a dynamic loading system condition. The modal analysis study results the specified natural frequency that must be avoided by the engineer in designing a typical dynamic system due to resonance structural loading. This paper presents numerical study of modal analysis of Alpha frames. Ten numbers of Eigenvalue for each designed frame have been obtain by implicit method simulation using LSDYNA. The result of this study will guide to determine and improve dynamic characteristics of E-Trike vehicle.

The main objective of this study is to obtain the natural frequency in the number of Eigenvalue. These natural frequencies are analysed to avoid the resonance of excitation frequency. Before prototyping and designing Beta frames which are developing at next stage, Alpha frame is required to be designed. In this study, frame types are investigated. Alpha frames of ETrike vehicle are the earliest basic frame design of the vehicle. Three earliest evolution design of Alpha frames which are Alpha-0, Alpha-1 and Alpha-2 are investigated.

\section{Design and simulation method}

\subsection{Alpha frame model}

CAD model was designed using CATIA V5R19. Surface model is generated as a basic design before it is simulated in numerical software. These basic frames are designed as a frame bearing the main loads both static and dynamics. A simple frame is designed on the main dimension of the vehicle to reduce the structural weight as much as possible. The design also considers the manufacturing process which must be simple such as bending forming and welding. Figure 1 shows isometric and 3D-view model of Alpha-0, Alpha-1, and Alpha-2 frame. The frames are built by seamless tubular JIS Schedule 40 [11] of different dimensions. Seamless tube used due to there is no welded joint on the tube circular.
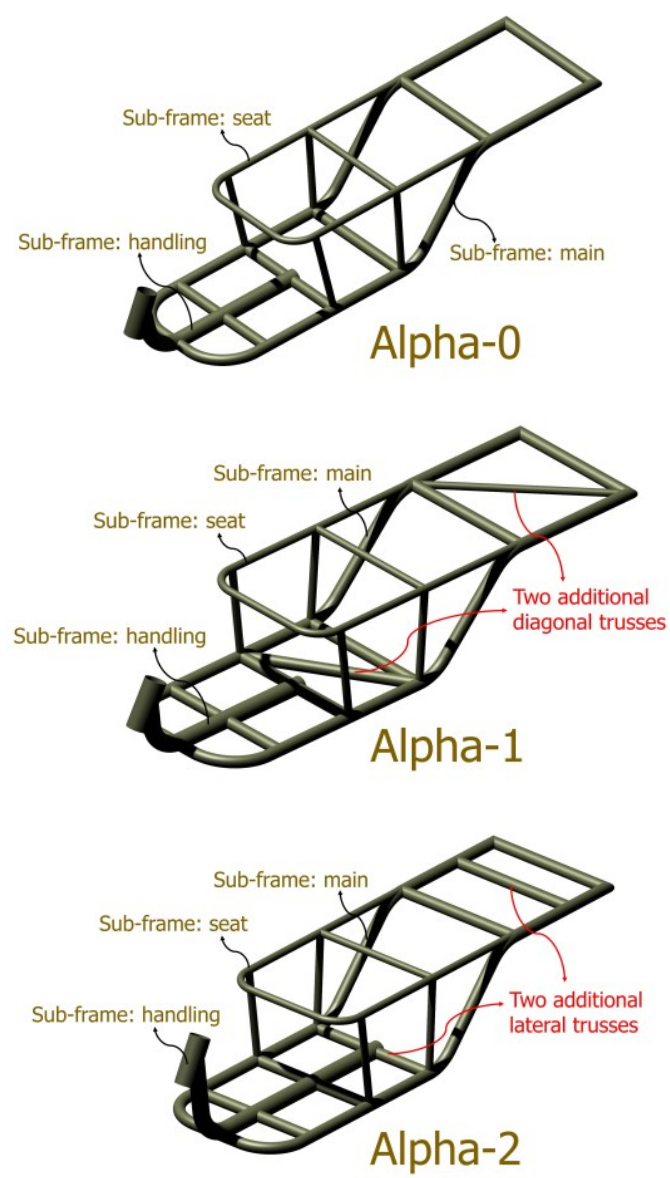

Fig. 1. Alpha frames model, these model is simulated to obtain the modal response. Three different Alpha configurations are built that consist of three sub frames; main frame, seat frame and handling frame. Modified configuration is conducted based on the Alpha- 0 as a basic frame.

There are two standards used in automotive terminology to define the vehicle axis system; ISO 8855(1991) [12] and SAE J670s [13]. SAE J670s on Vehicle Dynamics Terminology [13] that defines vehicle axis is also applied on this study to determine the vehicle modes. Multi body vehicle dynamics model is typically generated using right-handed axis system. In simple terms, $\mathrm{X}$-axis is a forward direction, $\mathrm{Y}$-axis is pointing to the right, and $\mathrm{Z}$-axis is down direction. Thus, $\mathrm{X}, \mathrm{Y}$, and $\mathrm{Z}$ are defined as longitudinal, lateral and vertical directions, respectively.

Alpha frames consist of three subparts which are the main frame, seat frame and handling frame. Handling frame is a curvature of seamless tubular steel that is attached by a set of bearing on the steering joint. The main frame is the main section where any other part is installed and bear the main loading through the frame joints. The seat frame is the sub-frame where the seat is installed. Three different seamless tubular diameters are used for optimum design by considering the load distribution. Alpha-0 which is the simplest configuration has five laterals and two longitudinal trusses. At the battery location, there is no stiffener truss, as well as at the goods location. This earliest frame also does not stretch the handling frame, the biggest tubular frame 
only reaches the second lateral truss. Alpha-1 and Alpha2 frames are developed based on the earlier design i.e. Alpha-0. The difference of those design is on the appearance of additional trusses that can increase the frame rigidity. Alpha-1 has a different configuration than the former frame. Alpha-1 and Alpha-2 has two additional trusses at the battery and goods location. Alpha-2 is also modified at the handling frame which is stretched up to the third truss. These additional modifications are intended to provide stiffener and strength for the frame at mobility and operational. Based on the design, the overall length of each frame is 2000 $\mathrm{mm}$ and width is $505 \mathrm{~mm}$. Alpha- 0 weight is $38.7 \mathrm{~kg}$, Alpha-1 weight is $42.2 \mathrm{~kg}$, and Alpha-2 weight is 42.7 $\mathrm{kg}$.

\subsection{Numerical Simulation}

Eigenvalues are investigated to obtain natural frequencies of a structure. Modal analysis of Alpha frames is performed using Lagrangian method of implicit numerical simulation in LS-DYNA. Number of Eigenvalues are recorded to evaluate the vibration modes. Alpha frames are generated as surface model in LS-DYNA. This surface is meshed as a shell element with $4 \mathrm{~mm}$ element size. $4 \mathrm{~mm}$ is enough sizing, compared to the overall dimension. It is not required to be smaller enough because the corner region is not the most concern for stress or displacement analysis [14].

Due to the complex geometry of frame, specific treatment on the $\mathrm{T}$-junction between surfaces is required to associate the mesh. A quadrangular element is chosen than a triangular element to simulate the modelling, due to more precise on stress distribution and deflection mode. Selected material of the frame is mild steel [15] and it is modelled as a simple material model *MAT3 PLASTIC KINEMATIC [16]. *MAT3 is determined since the modal analysis is assumed to ignore mechanical properties changing effects such as thermal sensitivity or strain rate effect. A simple linear stress strain curve is generated by this material model.

Boundary conditions represent Alpha frames in a real condition where the frame is restrained at some points due to contact with other components. The boundary conditions are fixed displacement at the steering axle and pin displacement (rotation free) at suspension join. On LS-Prepost [17], *CONTROL IMPLICIT is applied to simulate the model as an implicit method. *CONTROL IMPLICIT EIGENVALUE is applied to record the Eigenvalue result during the simulation.

\section{Results and discussion}

Three different Alpha frames were simulated in modal analysis numerical modelling. Numerical simulation for each frame type shows ten number of Eigenvalue modes. Based on the result, it is obtained the bending and torsion modes at axis for each frame subpart and whole frame. Ten different amplitudes occur at ten different Eigenvalues as shown in Table 1.
Figure 2 shows vibration modes of Alpha-0 frame. For Alpha- 0 , at the $1^{\text {st }}$ mode of $61.15 \mathrm{~Hz}$ bending mode on main frame occur at longitudinal axis. The amplitude is $11.42 \mathrm{~mm}$. The $2^{\text {nd }}$ mode occurs at $84.60 \mathrm{~Hz}$. Bending displacement of the seat frame is at $10.71 \mathrm{~mm}$. Torsional at both of main and seat sub frame occurs at $5^{\text {th }}$ mode. Combination of bending and torsional occurs on the whole frame at $248 \mathrm{~Hz}$ at the $10^{\text {th }}$ modes. Alpha-0 frame bends and twists at $\mathrm{X}$-axis. This combination mode, firstly appears at this Eigenvalue number. Where in the previous mode, each sub-frame with different deflection mode occurs at certain natural frequency.

Figure 3 shows vibration modes of Alpha-1 frame. $1^{\text {st }}$ and $2^{\text {nd }}$ mode show bending deflection at main and seat sub-frame. The first amplitude is $11.54 \mathrm{~mm}$ at $62 \mathrm{~Hz}$ and the second amplitude is $11.08 \mathrm{~mm}$ at $85.50 \mathrm{~Hz}$. Torsional mode of main and seat sub-frame is shown at $5^{\text {th }}$ mode. Combination of bending and torsional mode occurs at $247 \mathrm{~Hz}$ at $9^{\text {th }}$ mode for the whole frame. It can be seen that Alpha-1 frame becomes bend and longitudinal twist.

Figure 4 shows vibration modes of Alpha-2 frame. Similar to the others that the $1^{\text {st }}$ and $2^{\text {nd }}$ mode is a bending mode at main and seat sub-frame. The $1^{\text {st }}$ bending mode has an amplitude of $11.20 \mathrm{~mm}$ at 59.60 $\mathrm{Hz}$. The $2^{\text {nd }}$ vibration mode at $86 \mathrm{~Hz}$ has a maximum deflection of $10.90 \mathrm{~mm}$. Based on the result, less deflection occurs at these modes compared to the other frames. At $5^{\text {th }}$ mode, torsional deflection on main and seat sub-frame occurs at $164.90 \mathrm{~Hz}$. The result also shows that the whole frame shows the combination mode of bending and torsion at $12^{\text {th }}$ mode.

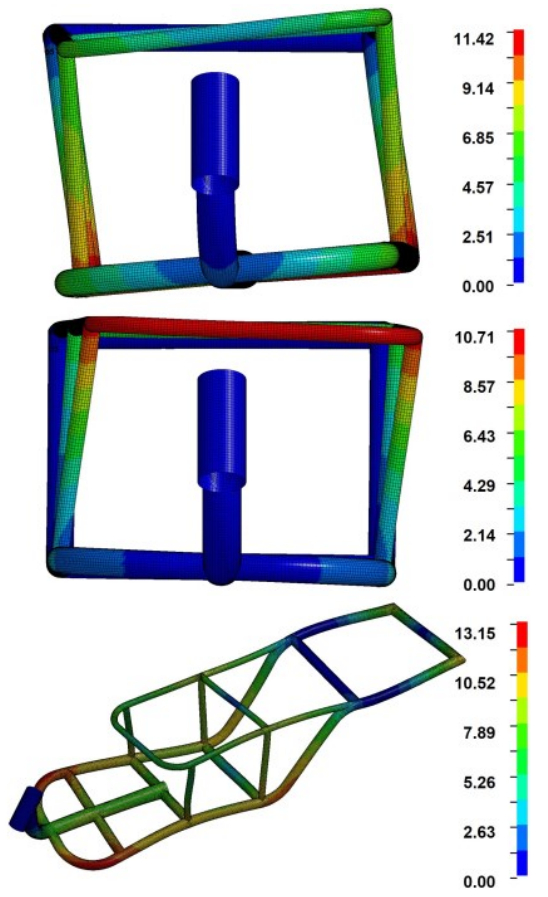

Fig. 2. Alpha-0 frame displacement $(\mathrm{mm})$ modal analysis for ten Eigenvalue modes. In sequence from top to bottom, $1^{\text {st }}$ mode shows the bending mode occurred at the main frame. $2^{\text {nd }}$ mode the bending mode of seat sub frame. $10^{\text {th }}$ mode shows the combination mode of torsion and bending of the vehicle. 

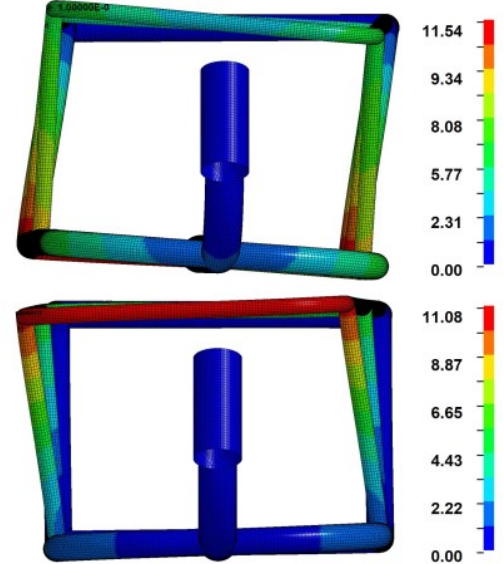

11.08
8.87
6.65
4.43
2.22
0.00

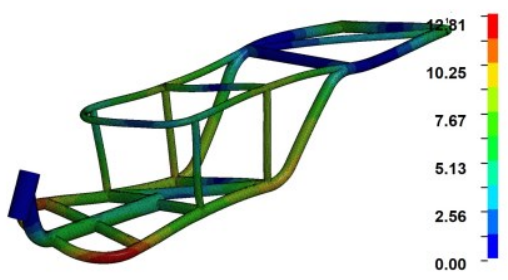

Fig. 3 Alpha-1 frame displacement (mm) modal analysis for ten Eigenvalue modes. In sequence from top to bottom, $1^{\text {st }}$ mode shows the bending mode occurred at the main frame. $2^{\text {nd }}$ mode the bending mode of seat sub frame. $9^{\text {th }}$ mode shows the combination mode of torsion and bending of the vehicle.

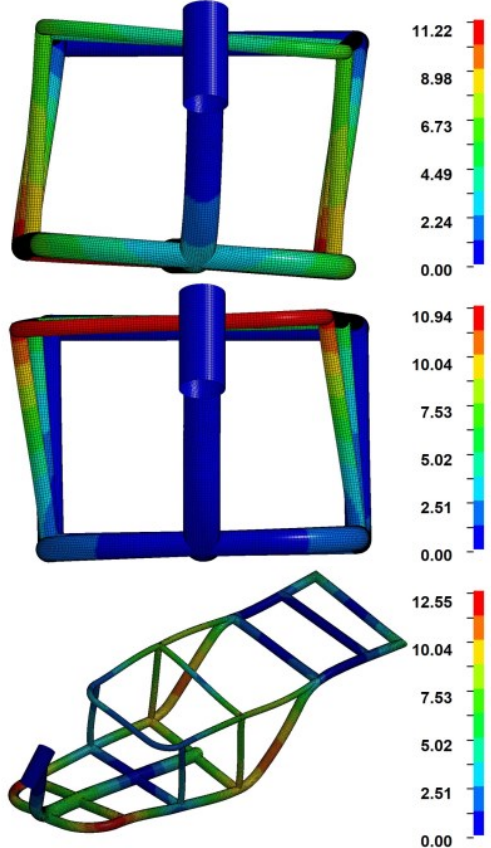

Fig. 4. Alpha-2 frame displacement (mm) modal analysis for ten Eigenvalue modes. In sequence from top to bottom, $1^{\text {st }}$ mode shows the bending mode occurred at the main frame. $2^{\text {nd }}$ mode the bending mode of seat sub frame. $12^{\text {th }}$ mode shows the combination mode of torsion and bending of the vehicle.

Table 1. Eigenvalues and modes location, it is shown that there is a vibration mode pattern at the same mode and position

\begin{tabular}{|c|c|c|c|c|c|c|}
\hline \multirow{2}{*}{ Eigenvalue } & \multicolumn{2}{|c|}{ Frame Alpha-0 } & \multicolumn{2}{c|}{ Frame Alpha-1 } & \multicolumn{2}{c|}{ Frame Alpha-2 } \\
\cline { 2 - 7 } & Modes & Position & Modes & Position & Modes & Position \\
\hline $1^{\text {st }}$ & Bending & Main & Bending & Main & Bending & Main \\
\hline $2^{\text {nd }}$ & Bending & Seat & Bending & Seat & Bending & Seat \\
\hline $3^{\text {th }}$ & Bending & Main & Bending & Main & Bending & Main \\
\hline $4^{\text {th }}$ & Bending & Main & Bending & Main & Bending & Main \\
\hline $5^{\text {th }}$ & Torsional & Main and seat & Torsional & Main and seat & Torsional & Main and seat \\
\hline $6^{\text {th }}$ & Bending & $\begin{array}{c}\text { Main (goods } \\
\text { location) }\end{array}$ & Bending & Main and seat & Bending & Main and seat \\
\hline $7^{\text {th }}$ & Bending & Seat & Bending & Seat & Torsional & Main and seat \\
\hline $8^{\text {th }}$ & Bending & whole frame & Torsional & $\begin{array}{c}\text { Main (goods } \\
\text { location) }\end{array}$ & Bending & Seat \\
\hline $9^{\text {th }}$ & Torsional & $\begin{array}{c}\text { Main (goods } \\
\text { location) }\end{array}$ & $\begin{array}{c}\text { Torsional } \\
\text { and Bending }\end{array}$ & whole frame & Bending & $\begin{array}{c}\text { Main (goods } \\
\text { location) }\end{array}$ \\
\hline $10^{\text {th }}$ & $\begin{array}{c}\text { Torsional and } \\
\text { Bending }\end{array}$ & whole frame & Bending & Seat & Torsional & $\begin{array}{c}\text { Main (goods } \\
\text { location) }\end{array}$ \\
\hline
\end{tabular}

Table 1 shows that Alpha frame has a pattern of vibration due to its Eigenvalue. The vibration at $1^{\text {st }}$ and $2^{\text {nd }}$ has same vibration modes of longitudinal bending deflection for main and seat sub-frame. $3^{\text {rd }}$ and $4^{\text {th }}$ modes are lateral bending deflection for the main frame. The $5^{\text {th }}$ mode occurs longitudinal torsional deflection on three Alpha frames. Combination between bending and torsion modes also occur for the frames after next several modes. Table 2 shows the natural frequency for Alpha frames at the same vibration modes which are $1^{\text {st }}$ bending, $2^{\text {nd }}$ bending, torsional and combination of both modes. It can also be seen that for the same vibration mode, natural frequencies of Alpha-0, Alpha-1 and Alpha-2 will be resonance at similar frequency range. At $1^{\text {st }}$ and $2^{\text {nd }}$ modes, longitudinal bending modes at about $60 \mathrm{~Hz}$ and $85 \mathrm{~Hz}$ on main and seat frame generate less than $12 \mathrm{~mm}$ deflection. Lateral main frame bending occurs at $3^{\text {rd }}$ and $4^{\text {th }}$ modes with relatively similar frequency ranges. The $5^{\text {th }}$ mode which is torsional deflection at longitudinal axis. Combination of torsional and bending mode occurs at later mode. Alpha- 0 shows this mode at $10^{\text {th }}$ mode with a natural frequency of $248.20 \mathrm{~Hz}$. Alpha-1 mode at the $9^{\text {th }}$ mode of $247.05 \mathrm{~Hz}$ and Alpha- 2 at the $12^{\text {th }}$ mode of $306.48 \mathrm{~Hz}$. 
Table 2. Natural frequencies of Alpha frames at same vibration modes. Most of the similar mode occurred at the same frequency range. The difference occurred due to the modified frame structure.

\begin{tabular}{|c|c|c|c|c|c|}
\hline \multicolumn{2}{|c|}{ Frame Alpha-0 } & \multicolumn{2}{c|}{ Frame Alpha-1 } & \multicolumn{2}{c|}{ Frame Alpha-2 } \\
\hline Frequency (Hz) & Eigenvalue & Frequency (Hz) & Eigenvalue & Frequency (Hz) & Eigenvalue \\
\hline 61.15 & $1^{\text {st }}$ & 62.00 & $1^{\text {st }}$ & 59.6 & $1^{\text {st }}$ \\
\hline 84.60 & $2^{\text {nd }}$ & 85.50 & $2^{\text {nd }}$ & 86.0 & $2^{\text {nd }}$ \\
\hline 111.40 & $3^{\text {rd }}$ & 107.19 & $3^{\text {rd }}$ & 106.5 & $3^{\text {rd }}$ \\
\hline 118.70 & $4^{\text {th }}$ & 115.29 & $4^{\text {th }}$ & 116.3 & $4^{\text {th }}$ \\
\hline 158.60 & $5^{\text {th }}$ & 162.44 & $5^{\text {th }}$ & 164.9 & $5^{\text {th }}$ \\
\hline 248.20 & $10^{\text {th }}$ & 247.05 & $9^{\text {th }}$ & 306.48 & $12^{\text {th }}$ \\
\hline
\end{tabular}

Figure 5 shows the comparison between amplitudes at the same vibration mode that Alpha- 2 has the least deflection for each mode. The result shows that the modification on Alpha-2 frame has affected on the amplitude deflection. The comparison on the same vibration mode is investigated. $1^{\text {st }}$ and $2^{\text {nd }}$ mode which is the same bending mode for the seat and main frame has reduced up to $3.04 \%$ on Alpha-2. This reduction is relatively small in deflection less than $1 \mathrm{~mm}$.

However, if Alpha frames are compared as shown in Table 3, it presents that Alpha-2 has biggest deflection to weight ratio. It can be said that Alpha-2 is the most optimum configuration due to the more weight can be compensated by the less deflection. The load distribution for Alpha-2 occurs lower at some point location. This could be because additional trusses are added at weakness point and increase the local stiffness. When the frame is vibrating, deflection is restraint by trusses. Alpha-2 prevents a load concentration to maintain the optimum design. This frame can avoid a structure failure cause by reducing the local deflection at corner location. Furthermore, the corner point is a location of trusses joint. Some trusses are assembled by metal welding. As a consequence, those locations will have the heataffected zone (HAZ) which changes the material properties. Residual stress will reduce the strength, the material is getting more brittle that can generate the weakest point on the frame. HAZ is inevitable. Local failure could lead a structure damage in vehicle design. As expected, the additional structure is positioned to strength the corner location. Further analysis on loading cases is required.

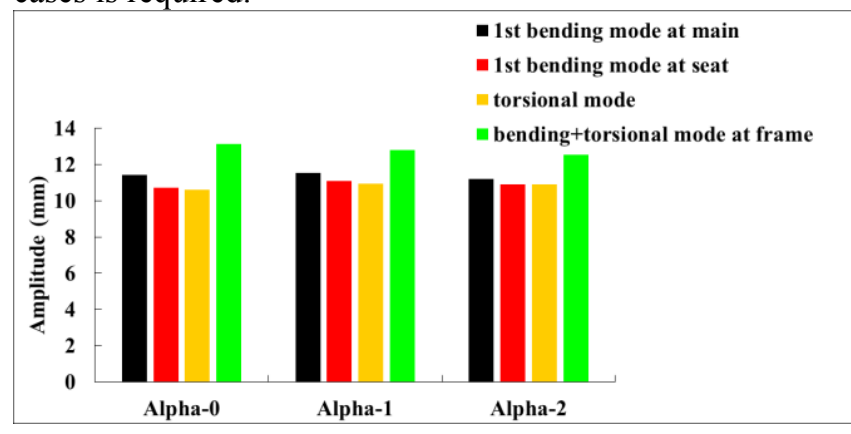

Fig. 5. Alpha frames amplitude during the $1^{\text {st }}$ bending mode at main and seat sub frame, torsional mode, and bending and torsional mode at frame. Amplitude records shows that Alpha2 configuration presents less deflection.
This could happen because the basic frame is same where Alpha-1 and Alpha-2 are designed based on the basic of Alpha-0 frame. Vehicle dimension (length and width) does not modified. The inertia of Alpha frames basically has a similar value at each axis. It means that the deflection mode would be also similar each other. Most of the vibration modes occur at longitudinal axis. This could be because of the frame geometry has basic rectangle frame with longer length from front to bottom at the longitudinal axis. The other thing that the constraint location where it also restrains the vehicle at front and bottom. The bottom joint which is suspension joint is rotation free that generates a wave movement between the handling point and shock breaker point. Furthermore, material properties used for frame material is also same with the earliest design. Mechanical properties of Young's modulus, inertia, dimension and system constraint determine the structure stiffness since the square root of stiffness by mass is a variable of natural frequency. Those aspects cause the number of waves and longitudinal deflection occurs at a relatively same position at similar frequency range.

Table 3. Deflection to weight ratio. Although Alpha-2 has the most weight, that is compensated by the least deflection at the vibration modes

\begin{tabular}{|c|c|c|c|c|}
\hline \multirow{2}{*}{ Frame } & \multicolumn{4}{|c|}{ Deflection to weight ratio } \\
\cline { 2 - 5 } & $\begin{array}{c}\mathbf{1}^{\text {st }} \\
\text { bending }\end{array}$ & $\begin{array}{c}\mathbf{2}^{\text {nd }} \\
\text { bending }\end{array}$ & torsional & $\begin{array}{c}\text { bending + } \\
\text { torsion }\end{array}$ \\
\hline Alpha-0 & 0.295 & 0.277 & 0.274 & 0.340 \\
\hline Alpha-1 & 0.273 & 0.262 & 0.259 & 0.303 \\
\hline Alpha-2 & 0.262 & 0.255 & 0.255 & 0.294 \\
\hline
\end{tabular}

Among this mode pattern, there are some other modes due to the complexity and shape differences of Alpha frames. Additional trusses configuration affects the vibration and generates another mode at each truss before whole frame bends and twists in a combination mode. Thus, combined mode of Alpha-2 occurs at different frequency ranges. Between the $9^{\text {th }}$ mode and $12^{\text {th }}$ mode, there are some additional vibrations for sub frame, respectively. Furthermore, the stretched sub frame affects by postponing the combination mode and generate the other mode in between of combination and $9^{\text {th }}$ mode. 


\section{Conclusion}

Ten Eigenvalue analysis of each Alpha frame has executed by using an implicit method of LSDYNA. Modal analysis of three frames results in the amplitude and natural frequency responses. The maximum amplitude of three Alpha frames is less than $15 \mathrm{~mm}$. It can be noticed that there is a pattern of vibration modes due to the frame deflection at modal analysis. Three Alpha frames have same natural frequency range at the same vibration mode. Deflection at some location during the vibration mode generates bending and torsion of frame.

At $1^{\text {st }}$ and $2^{\text {nd }}$ mode, Alpha frames resonance at the frequency range of 59-62 Hz and $84-86 \mathrm{~Hz}$, respectively. Maximum amplitude of $11.54 \mathrm{~mm}$ at the center position at the cross bar of Alpha-1. Less deflection occurs on Alpha-2 with $11.20 \mathrm{~mm}$ or reduces $3 \%$ of deflection. Amplitude result shows that Alpha-2 frame has a good configuration among three-wheel chassis. Alpha frame occurs a combination of bending and torsional mode at frequency range of $245-250 \mathrm{~Hz}$.

The result of natural frequencies must be avoided by E-Trike engineer when designing the prototype. Continuous improvement on frame design may be conducted if the excitation has close or similar to the frame natural frequency. A comprehensive study on this simulation presents that the advantage of modal analysis will be used to improve and optimize the chassis design. A continuous design process is conducted based on this study to determine E-Trike Beta frame by changing the design or change the load constraint location.

This paper supported by USAID through Sustainable Higher Education Research Alliances (SHERA) program with grant number IIE00000078-ITB-1. Additional information concerning E-Trike project is available at www.ncstt.itb.ac.id.

\section{References}

[1] L. Hollmotz, S. Sohr, and H. Johannsen. 19th Int. Tech. Conf. on the Enhanced Safety of Vehicles (ESV) (2005).

[2] A. van Poelgeest. The Dynamics and Control of $A$ Three-Wheeled Tilting Vehicle, University of Bath. (2011)

[3] D. Cao, Xubin Song, and M. Ahmadian. J. Veh. Syst. Dyn. 49, 3-28 (2010)

[4] A. Jusuf, T. Dirgantara, L. Gunawan, and I. S. Putra. Int. J. Impact Eng. 78, 34-50 (2015)

[5] A. P. Kumar, M. N. Mohamed, A. Jusuf, T. Dirgantara, and L. Gunawan. Thin-Walled Struct. 124, 468-488 (2018)

[6] V. P. Zolotarevich, A. E. Salienko, A. I. Frumen, and N. V. Yugov. Proc. Struct. Integr. 6, 224-227 (2017)

[7] A. J. Muminovic, S. Braut, A. Muminovic, and I. Saric. TEM J. 3, 323-328 (2014)

[8] H. Zhu, Y. Hu, and W. D. Zhu. Eur. J. Mech. A / Solids. 67, 137-156 (2018)
[9] D. Turcanu, I. Nicola, T. Prosecaru, and C. Predoi. Rom. Reports Phys. 68 (2016)

[10] R.R Craig Jr., Structural Dynamics. Wiley (1976)

[11] ISO. ISO 8855: Road vehicles - Vehicle dynamics and road-holding ability - Vocabulary (2011)

[12] Japan Industrial Standard. JIS G 3454: Carbon steel pipes for pressure service (2005)

[13] SAE. SAE J670 Vehicle Dynamics Terminology (2008)

[14] W. Liu, M. Geni, and L. Yu. Key Eng. Mater. 462-463, 1008-1012 (2011)

[15] Overview of materials for Low Carbon Steel, Material Property Data - MatWeb. [Online]. Available:

http://www.matweb.com/search/DataSheet.aspx? MatGUID=034970339dd14349a8297d2c8313464 9.

[16] LSTC, LS-DYNA: Keywords User's Manual II Material Model, vol. II. (2017)

[17] LSTC, LS-DYNA: Keywords User's Manual I, vol. II (2017). 